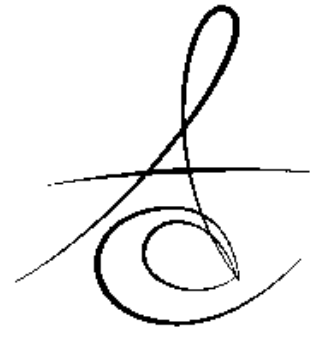

Makale Kodu/Article code: 1805

Makale Gönderilme tarihi: 25.07.2014

Kabul Tarihi: 01.10.2014

\title{
PROTEZ TEMİZLEYİCİLERİNİN YUMUŞAK ASTAR MADDELERİNİN RENK STABİLİTELERİ ÜZERİNE ETKİSİNİN DEĞERLENDİRİLMESİ
}

\section{THE EFFECT OF DENTURE CLEANSERS ON THE COLOR STABILITY OF SOFT DENTURE LINING MATERIALS}

\author{
Yrd. Doç. Dr. Sevcan KURTULMUŞ-YILMAZ* Doç. Dr. Oğuz OZAN* \\ Dr. Dt. Serhat RAMOĞLU* \\ Arş. Gör. Dt. Hüseyin AKTÖRE* \\ Arş. Gör. Dt. Abdullah Oğuz HAMİ̧̧*
}

\section{ÖZET}

Amaç: Bu çalışmanın amacı uzun süreli silikon esası yumuşak astar maddelerinin renk stabiliteleri üzerine farklı protez temizleyicilerinin etkilerinin değerlendirilmesidir.

Materyal ve Metod: Bu çalışmada 2 farklı silikon esaslı yumuşak astar maddesi (Elite Soft ve Ufi Gel P) ile 3 farklı protez temizleyicisi [Corega Tabs, Fittydent, $\% 0.5$ sodyum hipoklorit $(\mathrm{NaOCl})]$ test edilmiş; distile su kontrol grubu olarak kullanılmıştır. Her yumuşak astar maddesinden $10 \mathrm{~mm}$ çapında ve $1 \mathrm{~mm}$ kalınlığında toplam 40 adet disk şeklinde örnek hazırlanmıştır $(n=10)$. Protez temizleyicisine maruz bırakılmadan önce tüm örneklerin CIE L*a*b* değerleri spektrofotometre ile tespit edilmiştir. Uygulanacak temizleme prosedürüne göre rastgele 4 ayrı gruba ayrılan örnekler 8 saat protez temizleyicisine maruz bırakılmış daha sonra akan suda yıkanarak 16 saat boyunca distile suda bekletilmiştir. Bu işlem 96 gün boyunca tekrarlanmış; her 3 günlük periyot 1 hafta olarak kabul edilmiş ve böylece 6 aylık kullanım simüle edilmiştir. Renk ölçümleri sırasıyla 3 ve 6 ayı simüle eden, 48. ve 96 . günün sonunda tekrarlanmıştır. Renk farkı değeri $(\Delta \mathrm{E})$ hesaplanarak veriler istatistiksel olarak analiz edilmiştir.

Bulgular: Ufi Gel $P$, Elite Soft'a göre istatistiksel olarak anlamlı derecede düşük $\Delta \mathrm{E}$ değerleri göstermiştir $(P<0.05)$. Protez temizleyicileri kıyaslandığında, $\mathrm{NaOCl}$ grubu diğer protez temizleyicilerine ve kontrol grubuna göre daha yüksek renk farkına neden olmuş $(P<0.05)$; Corega Tabs, Fittydent ve kontrol grubu arasında ise istatistiksel olarak anlamlı bir farklılık bulunamamıştır $(P>0.05)$.

Sonuç: Renk stabilitesi, materyalin yıpranması ve zarar görmesi hakkında klinisyenlere fikir veren bir belirteçtir. Bu nedenle, yumuşak astar maddelerinde protez temizleyicileri nedeniyle oluşan renk farkı materyal seçiminde göz önünde bulundurulmalıdır.

Anahtar kelimeler: Silikon, spektrofotometre, sodyum hipoklorit, alkali peroksit

\section{ABSTRACT}

Aim: The aim of this study was to evaluate the effect of denture cleansers on the color stability of long-term soft denture lining materials.

Materials and Method: Two different silicone soft lining materials (Elite Soft and Ufi Gel P) and 3 different denture cleansers [Corega Tabs, Fittydent, $0.5 \%$ sodium hypochlorite $(\mathrm{NaOCl})]$ were used in this study and distilled water was served as control group. Forty disc-shaped specimens, with $10 \mathrm{~mm}$ in diameter and $1 \mathrm{~mm}$ in thickness were fabricated from each soft lining material $(n=10)$. CIE L*a*b* values of specimens were recorded with a spectrophotometer and then specimens were randomly divided into 4 groups according to the cleaning protocol. All of the specimens were immersed in denture cleansers for 8 hours, then washed under running water and after that stored in distilled water for 16 hours. This procedure was repeated for 96 days; every 3 days were considered as 1 week and thus 6-month of usage was simulated. Color measurements were repeated at the end of 48 and 96 (Nokta kaldırılsın) days and color differences $(\Delta \mathrm{E})$ were calculated. Data were statistically analyzed.

Result: Ufi Gel P showed significantly lower $\Delta \mathrm{E}$ values in comparison to Elite Soft $(\mathrm{P}<0.05)$. $\mathrm{NaOCl}$ demonstrated higher color differences than the other cleansers and control group $(P<0.05)$; however there was no significantly difference among Corega Tabs, Fittydent and control group ( $P>0.05)$.

Conclusion: Since color stability of soft liners is an important indicator for clinicians of aging or damaging, the color difference in soft liners caused by the denture cleansers should be taken into consideration in material selection.

Key words: Silicone, spectrophotometer, sodium hypochlorite, alkaline peroxide

*Yakın Doğu Üniversitesi Diş Hekimliği Fakültesi, 


\section{GİRIŞ}

Aşırı rezorbe ve bıçak sırtı kretler, kemik andırkatları, ince mukoza, ağız kuruluğu, karşıt çenede doğal dişlerin varlığında veya bruksizme eğilimli hastalarda hareketli proteze destek olan bölgeler sert kaide materyalinin basıncına karşı hassas olabilmektedir. ${ }^{1-3}$ Bu gibi durumlarda, elastik yapıdaki yumuşak astar maddelerinin kullanımı ile enflame mukozanın iyileşmesi sağlanır; ${ }^{4}$ fonksiyonel yük proteze destek olan alanlar arasında eşit dağıtılır; ${ }^{5}$ protezin uyumu ve retansiyonu arttırılır. ${ }^{6}$ Yumuşak astar maddeleri kullanım sürelerine göre kısa veya uzun süreli; kompozisyonlarına göre akrilik ve silikon; polimerizasyon şekillerine göre de kimyasal, ısı ve ışık ile polimerize olan şeklinde sınıflandırılabilirler. ${ }^{7,8}$ Kısa süreli yumuşak astar maddeleri 30 güne kadar kullanılabilirken, ${ }^{9}$ uzun süreli olanlar 1 yıl veya daha uzun süre ağızda kalabilirler. ${ }^{10}$

Yumuşak astar maddelerinin yapısı ve yüzeylerinin pürüzlü olması oral mikroorganizmaların kolonizasyonunu kolaylaştırmaktadır. ${ }^{11,12}$ Plak, protez stomatitinin etiyolojisindeki ana faktör olduğu için, yumuşak astar maddelerinin yüzeyinde etkili bir plak kontrolü sağlanması oldukça önemlidir. ${ }^{13}$ Plak kontrolünde diş fırçası (mekanik yöntem) veya protez temizleyicileri (kimyasal yöntem) kullanılabilir. Ancak fırçalama yumuşak astar maddesine zarar verebileceği için protez temizleyicilerinin kullanımı önerilmektedir. ${ }^{8,14}$

Protez temizleyicileri içeriklerine göre; alkali peroksitler, alkali hipokloritler, asitler, dezenfektanlar ve enzimler şeklinde sınıflandırılabilirler. ${ }^{14}$ Protez temizleyicilerinin C. albicans kolonizasyonu ve plak oluşumunu engellemede etkili olduğu düşünülmekle birlikte ${ }^{15}$ bazı protez temizleyicilerinin, yumuşak astar maddelerinin fiziksel ve mekanik özelliklerini etkileyebildiği rapor edilmiştir. ${ }^{12,13,16} \mathrm{Bu}$ nedenle protez temizleyicilerinin seçiminde astar maddesinin kompozisyonu da göz önünde bulundurulmalıdır. ${ }^{17,18}$

Dental materyaller için en önemli özelliklerden birisi renk stabilitesidir. Renk stabilitesi estetik görünümün devam etmesini sağlamakla birlikte, materyalin yıpranması ve zarar görmesi hakkında da klinisyenlere fikir vermektedir. ${ }^{19} \mathrm{Bu}$ nedenle, özellikle uzun süreli yumuşak astar maddelerinde renk stabilitesi daha fazla önem kazanmaktadır. ${ }^{17,20}$ Yaşlandırma işlemlerinin ${ }^{20-23}$ ve renklendirici gıdaların ${ }^{24-27}$ yumuşak astar maddelerinin renk stabiliteleri üzerinde etkili olduğu birçok çalışmada tespit edilmiş ve akrilik esaslı yumuşak astar maddelerinin silikon esaslı olanlara kıyasla daha düşük renk stabilitesi gösterdikleri rapor edilmiştir. ${ }^{20,22,25}$ Literatür incelendiğinde, protez temizleyicilerinin yumuşak astar maddelerinin renk stabiliteleri üzerindeki etkileri hakkında sınırlı sayıda araştırma ${ }^{17,18}$ olduğu gözlenmiştir.

$\mathrm{Bu}$ çalışmanın amacı farklı protez temizleyicilerinin uzun süreli silikon esaslı yumuşak astar maddelerinin renk stabiliteleri üzerine etkilerinin değerlendirilmesidir.

\section{GEREÇ ve YÖNTEM}

Çalışmada kullanılan silikon esaslı yumuşak astar maddeleri ve protez temizleyicileri Tablo 1'de gösterilmiştir. Yumuşak astar maddelerinden, üretici firmanın talimatları doğrultusunda, $10 \mathrm{~mm}$ çapında ve $1 \mathrm{~mm}$ kalınlığında 40'ar adet disk şeklinde örnek hazırlanmıştır $(n=10)$. Örnekler, renk ölçümleri yapılmadan önce, 24 saat süreyle $37^{\circ} \mathrm{C}$ sıcaklıktaki distile suda bekletilmiştir.

Tablo 1. Çalışmada kullanılan materyaller.

\begin{tabular}{|c|c|c|c|}
\hline Materyal & Ürün & İçerik & $\begin{array}{l}\text { Üretici } \\
\text { firma }\end{array}$ \\
\hline $\begin{array}{l}\text { Yumuşak } \\
\text { astar } \\
\text { maddesi }\end{array}$ & $\begin{array}{l}\text { Elite Soft } \\
\text { Relining }\end{array}$ & Vinil polisiloksan & $\begin{array}{l}\text { Zhermack, } \\
\text { Badia- } \\
\text { Polesine, } \\
\text { İtalya }\end{array}$ \\
\hline $\begin{array}{l}\text { Yumuşak } \\
\text { astar } \\
\text { maddesi }\end{array}$ & Ufi Gel P & $\begin{array}{l}\text { Modifiye } \\
\text { polidimetilsiloksan }\end{array}$ & $\begin{array}{l}\text { Voco, } \\
\text { Cuxhaven, } \\
\text { Almanya }\end{array}$ \\
\hline $\begin{array}{l}\text { Protez } \\
\text { temizleyicisi }\end{array}$ & $\begin{array}{l}\text { Corega } \\
\text { Tabs }\end{array}$ & $\begin{array}{l}\text { Potasyum } \\
\text { monopersülfat, } \\
\text { sodyum } \\
\text { bikarbonat, } \\
\text { sodyum lauril } \\
\text { sülfoasetat, } \\
\text { sodyum perborat } \\
\text { monohidrat, } \\
\text { sodyum polifosfat }\end{array}$ & $\begin{array}{l}\text { Block Drug } \\
\text { Company, } \\
\text { New Jersey, } \\
\text { Amerika }\end{array}$ \\
\hline $\begin{array}{l}\text { Protez } \\
\text { temizleyicisi }\end{array}$ & Fittydent & $\begin{array}{l}\text { Sodyum perborat, } \\
\text { sodyum } \\
\text { bikarbonat, } \\
\text { potasyum } \\
\text { monopersülfat, } \\
\text { trisodyum fosfat, } \\
\text { sülfamik asit }\end{array}$ & $\begin{array}{l}\text { Fittydent } \\
\text { International } \\
\text { GmbH, } \\
\text { Pinkafeld, } \\
\text { Avusturya }\end{array}$ \\
\hline $\begin{array}{l}\text { Protez } \\
\text { temizleyicisi }\end{array}$ & $\begin{array}{l}\text { Sodyum } \\
\text { hipoklorit } \\
\text { (NaOCl) }\end{array}$ & $\begin{array}{l}\text { Su, \%0.5 sodyum } \\
\text { hipoklorit }\end{array}$ & - \\
\hline
\end{tabular}

Örneklerin CIE $L^{*} a * b *$ değerleri klinik spektrofotometre (VITA Easyshade Compact, Vita Zahnfabrik, Almanya) ile ölçülmüştür. VITA Easyshade Compact,

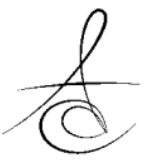


Atatürk Üniv. Diş Hek. Fak. Derg.

J Dent Fac Atatürk Uni

Cilt:25, Sayı:1, Yıl: 2015, Sayfa: 59-65

çok sayıda fiberoptik ışık demeti içeren yaklaşık $5 \mathrm{~mm}$ çapında ölçüm ucuna sahip, kablosuz bir el aparatından oluşmaktadır. Renk ölçümü sırasında materyal yüzeyi beyaz LED ışıklarla aydınlatılmaktadır. Cihaz ölçüm sonucunu klasik VITA skalasına, VITA Tooth Guide 3D Master skalasına ve CIE L*a*b* renk sistemine göre vermektedir. Spektrofotometre, her ölçüm öncesinde üretici talimatlarına uygun şekilde kalibre edilmiştir. Örnekler nötral gri bir arka plan ( $L^{*}=46.6$, $\left.a^{*}=2.5, \quad b^{*}=-0.8\right)$ üzerine yerleştirilmiş ve ölçümler cihazın "toothsingle" modunda yapılmıştır. Her örnekten 3 ölçüm yapılmış ve bu ölçümlerin ortalaması alınmıştır.

Renk ölçümleri sonrası örnekler, uygulanacak temizleme prosedürüne göre rastgele 4 ayrı gruba ayrılmıştır. Her yumuşak astar maddesinden bir grup, kontrol grubu olarak kullanılmış ve karanlık bir odada distile su içinde bekletilmiştir. Protez temizleyicileri üretici firmaların talimatları doğrultusunda hazırlanmıştır. Her grup ilgili protez temizleyicisine 8 saat süreyle maruz bırakılmış; daha sonra akan suda yıkanarak 16 saat boyunca distile suda bekletilmiştir. Bu işlem 96 gün boyunca tekrarlanmış; her 3 günlük periyot 1 hafta olarak kabul edilmiş ve böylece 6 aylık kullanım simüle edilmiştir. Renk ölçümleri sırasıyla 3 ve 6 ayı simüle eden, 48. ve 96. günün sonunda tekrarlanmıştır. Başlangıç ile 3 ve 6 ay uygulama sonrasındaki renk farkı değeri $(\Delta \mathrm{E})$ aşağıdaki formül kullanılarak hesaplanmıştır:

$$
\Delta \mathrm{E}=\left[\left(\Delta \mathrm{L}^{*}\right)^{2}+\left(\Delta \mathrm{a}^{*}\right)^{2}+\left(\Delta \mathrm{b}^{*}\right)^{2}\right]^{1 / 2}
$$

Delta $L^{*}, \Delta a^{*}$ ve $\Delta b^{*}$, başlangıç ile farklı zaman aralıklarında ölçülen $L^{*}, a^{*}$ ve $b^{*}$ değerleri arasındaki farkı göstermektedir.

Renk farkı $(\Delta \mathrm{E})$ değerini değerlendirmede National Bureau of Standards (NBS) tarafından tanımlanan NBS değerleri (Tablo 2) kullanılmıştır. NBS değerleri aşağıdaki formül kullanılarak hesaplanmıştır:

NBS değeri $=\Delta \mathrm{E} \times 0.92$

Tablo 2. National Bureau of Standards (NBS) tarafindan tanımlanan renk farkı kriterleri.

\begin{tabular}{|l|l|}
\hline NBS değeri & Renk farkı \\
\hline $0.0-0.5$ & Çok az \\
\hline $0.5-1.5$ & Az, belirsiz \\
\hline $1.5-3.0$ & Fark edilebilir \\
\hline $3.0-6.0$ & Belirgin \\
\hline $6.0-12.0$ & Fazla \\
\hline$>12.0$ & Çok fazla \\
\hline
\end{tabular}

KURTULMUŞ-YILMAZ, OZAN, RAMOĞLU AKTÖRE, HAMIŞ

Verilerin istatistiksel analizinde, yumuşak astar maddelerinin renk değişiminin kıyaslanmasında t-testi; protez temizleyicilerinin renk farkına etkisinin değerlendirilmesinde tek yön ANOVA ve Tukey testi; uygulama süresinin etkisinin incelenmesinde çift örnekler ttesti kullanılmıştır.

\section{BULGULAR}

Yumuşak astar maddelerinin protez temizleyicilerine 3 ve 6 ay süreyle maruz bırakılması sonucu elde edilen ortalama $\Delta \mathrm{E}$ değerleri, standart sapmaları ve ortalama NBS değerleri Tablo 3 ve Şekil 1'de görülmektedir. Tüm $\Delta \mathrm{E}$ değerleri incelendiğinde, Ufi Gel $\mathrm{P}$ yumuşak astar maddesi Elite Soft Relining'e göre istatistiksel olarak anlamlı derecede daha az renk değişimi göstermiştir $(P<0.001)$.

Tablo 3. Yumuşak astar maddelerinde oluşan ortalama renk farkı $(\Delta \mathrm{E})$, standart sapma (SS) ve ortalama NBS değerleri.

\begin{tabular}{|c|c|c|c|c|c|c|c|}
\hline \multirow[b]{2}{*}{ Materyal } & \multirow{2}{*}{$\begin{array}{c}\text { Protez } \\
\text { temizleyici }\end{array}$} & \multicolumn{3}{|c|}{ 3. ay } & \multicolumn{3}{|c|}{ 6. ay } \\
\hline & & $\begin{array}{l}\Delta E 1 \\
\text { (SS) }\end{array}$ & $\begin{array}{c}\text { Istatis } \\
\text {-tik } \\
\text { grup }\end{array}$ & $\begin{array}{c}\text { NBS } \\
1\end{array}$ & $\begin{array}{l}\Delta E 2 \\
( \pm S S)\end{array}$ & $\begin{array}{c}\text { Istatis- } \\
\text { tik } \\
\text { grup }\end{array}$ & $\begin{array}{l}\text { NBS } \\
2\end{array}$ \\
\hline \multirow[t]{4}{*}{ Ufi Gel P } & Distile su & $\begin{array}{c}0.7 \\
(0.48)\end{array}$ & $A^{*}, a^{\#}$ & 0.6 & $\begin{array}{c}2.1 \\
(0.84)\end{array}$ & $\mathrm{F}, \mathrm{b}$ & 1.9 \\
\hline & Corega & $\begin{array}{c}1.1 \\
(0.36)\end{array}$ & $A, C, C$ & 1.0 & $\begin{array}{c}1.2 \\
(0.34) \\
\end{array}$ & $\mathrm{F}, \mathrm{C}$ & 1.1 \\
\hline & Fittydent & $\begin{array}{c}1.1 \\
(0.63)\end{array}$ & $A, C, d$ & 1.1 & $\begin{array}{c}3.0 \\
(1.27)\end{array}$ & $\mathrm{F}, \mathrm{e}$ & 2.7 \\
\hline & $\mathrm{NaOCl}$ & $\begin{array}{c}1.7 \\
(1.02)\end{array}$ & $B, C, f$ & 1.6 & $\begin{array}{c}2.2 \\
(0.99)\end{array}$ & $F, f$ & 2.0 \\
\hline \multirow[t]{4}{*}{$\begin{array}{l}\text { Elite Soft } \\
\text { Relining }\end{array}$} & Distile su & $\begin{array}{c}4.4 \\
(0.79)\end{array}$ & $D, g$ & 4.0 & $\begin{array}{c}6.4 \\
(1.52)\end{array}$ & $\mathrm{G}, \mathrm{h}$ & 5.9 \\
\hline & Corega & $\begin{array}{c}3.5 \\
(0.63) \\
\end{array}$ & $D, i$ & 3.3 & $\begin{array}{c}4.8 \\
(0.74)\end{array}$ & $G, j$ & 4.5 \\
\hline & Fittydent & $\begin{array}{c}4.3 \\
(0.93)\end{array}$ & $\mathrm{D}, \mathrm{k}$ & 3.9 & $\begin{array}{c}6.2 \\
(0.74)\end{array}$ & G, I & 5.7 \\
\hline & $\mathrm{NaOCl}$ & $\begin{array}{c}29.6 \\
(1.68) \\
\end{array}$ & $E, m$ & 27.3 & $\begin{array}{c}30.5 \\
(2.21) \\
\end{array}$ & $\mathrm{H}, \mathrm{m}$ & 28.0 \\
\hline
\end{tabular}

*Protez temizleyicilerinin renk farkına etkisinin tek yön ANOVA ve Tukey testi ile değerlendirilmesi sonucu, aynı büyük harflerle kodlanan gruplar arasında istatistiksel fark bulunmamaktadır $(P>0.05)$.

${ }^{\#}$ Sürenin renk farkına etkisinin t-testi ile değerlendirilmesi sonucu, aynı küçük harflerle kodlanan gruplar arasında istatistiksel fark bulunmamaktadır $(P>0.05)$. 


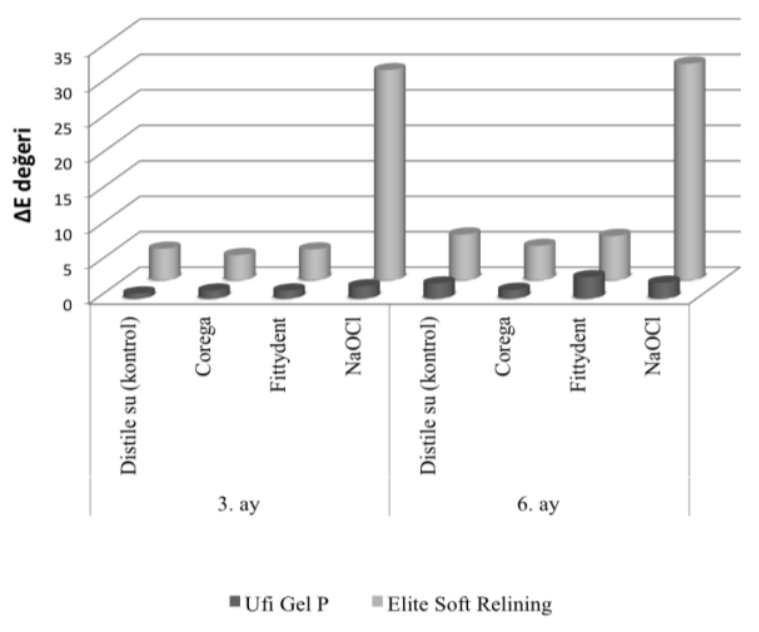

Şekil 1. Yumuşak astar maddelerinin protez temizleyicilerine 3 ve 6 ay süreyle maruz bırakılması sonucu elde edilen ortalama $\Delta \mathrm{E}$ değerleri

Üçüncü ay sonunda, Ufi Gel P için protez temizleyicilerinin renk farkına etkisi değerlendirildiğinde, Corega ve Fittydent ile kontrol grubu (distile su) arasında anlamlı bir fark bulunmazken ( $P>0.05$ ); sodyum hipokloritin $(\mathrm{NaOCl})$ anlamlı derecede daha fazla renk değişimine neden olduğu tespit edilmiştir ( $P$ $<0.05$ ) (Tablo 3). Üçüncü ayın sonunda elde edilen $\triangle \mathrm{E}$ değerlerinin NBS skorlaması incelendiğinde, kontrol grubu (0.6), Corega (1.0) ve Fittydent'in (1.1) az/ belirsiz miktarda; NaOCl'nin (1.6) ise fark edilebilir bir renk değişimine neden olduğu bulgulanmıştır (Tablo 2 ve 3). Altıncı ay sonundaki $\Delta \mathrm{E}$ değerleri analiz edildiğinde, protez temizleyicileri ile kontrol grubu arasında istatistiksel olarak anlamlı bir fark bulunamamıştır ( $P$ > 0.05) (Tablo III). NBS skorlarına göre Corega (1.1) az/belirsiz bir renk farkı oluştururken; kontrol grubu (1.9), Fittydent (2.7) ve NaOCl'de (2.0) fark edilebilir renk değişiklikleri belirlenmiştir (Tablo 2 ve 3 ). Protez temizleyicilerinin uygulama sürelerinin renk değişimi üzerinde etkisi değerlendirildiğinde, Corega ve $\mathrm{NaOCl}$ için 3. ve 6. aydaki değerler arasında anlamlı bir fark bulunamamıştır (sırasıyla $P=0.263$ ve $P=0.357$ ). Kontrol grubu ve Fittydent'de uygulama süresi arttıkça renk değişimin de anlamlı derecede arttığı görülmüştür $(P<0.05)$ (Tablo 3).

Elite Soft Relining'e ait $\Delta \mathrm{E}$ değerleri analiz edildiğinde, 3. ve 6. ay sonunda kontrol grubu, Corega ve Fittydent arasında istatistiksel olarak anlamlı bir fark bulunamamış ( $P>0.05$ ); $\mathrm{NaOCl}$ grubunda ise anlamlı derecede fazla renk farkı tespit edilmiştir $(P<$
0.001). Kontrol grubu, Corega ve Fittydent'e maruz bırakılan örneklerde oluşan renk farkı uygulama süresinin artmasıyla anlamlı derecede artış göstermiştir. NBS skorları incelendiğinde, hem 3. hem de 6. ayın sonunda belirgin derecede renk değişimi olduğu belirlenmiştir. $\mathrm{NaOCl}$ grubunda ise 3. ve 6. ayda ölçülen $\Delta \mathrm{E}$ değerleri arasında istatistiksel olarak bir fark gözlenmezken ( $P=0.556)$, oluşan renk farkı NBS kriterlerine göre çok fazla olarak tanımlanmıştır (Tablo 2 ve 3 ).

\section{TARTIŞMA}

Yumuşak astar maddelerinin renk stabilitesi, hastanın memnuniyetini ve protezi kabul etmesini etkileyen en önemli faktörlerden biridir. ${ }^{19,28}$ Günümüzde yumuşak astar maddelerinin fiziksel özellikleri çok geliştirilmiş olmakla birlikte, halen su emilimi, çözünürlük ve renk değişimi gibi dezavantajları bulunmaktadır. ${ }^{29}$ Herhangi bir renklendirici solüsyona maruz bırakılmadan gözlenen renk değişimi materyalin kimyasal yapısındaki değişiklikleri gösteren bir belirteç olabilmektedir. ${ }^{13}$ Bu çalışmada, protez temizleyicilerinin 3 ve 6 aylık kullanımı simüle edilerek, uzun süreli yumuşak astar maddelerinin renk stabiliteleri üzerindeki etkileri değerlendirilmiştir. Renk farkının belirlenmesinde, yaygın olarak kullanılan ve kromatik farklılıkları matematiksel verilere dönüştürebilen 3 boyutlu CIE L*a*b* renk sistemi tercih edilmiştir. ${ }^{30}$ Ayrıca $\Delta \mathrm{E}$ değerlerinin karşılaştırılmasında ve klinik olarak yorumlanabilmesinde önemli bir parametre olan NBS kriterleri de kullanılmıştır. ${ }^{31,32}$

Protez temizleyicilerinin yumuşak astar maddelerinin yapısından bileşiklerin salınımına neden olduğu gösterilmiştir. Bu bileşiklerin salınımı materyallerin elastisitelerinde azalmaya sebep olmaktadır. ${ }^{16}$ Bunun yanında plastikleştiricilerin, monomerlerin ve pigmentlerin salınımı da materyalde renk değişimine yol açabilir. ${ }^{33,34}$ Akrilik rezin ve silikon esaslı yumuşak astar maddelerinin renk stabiliteleri kıyaslandığında, silikon esaslı materyallerin daha yüksek renk stabilitesi gösterdiği belirtilmiştir. ${ }^{18,25,28}$ Bunun nedeninin, akrilik rezin esaslı materyallerin daha yüksek su emilimine sahip olması ve daha fazla çözünürlük göstermesi olduğu öne sürülmektedir. Silikon esaslı materyallerin hidrofobik karakterde olmasının, materyalin daha az su emilimine sahip olmasını sağladığı düşünülmektedir. ${ }^{35,36} \mathrm{Bu}$ çalışmada test edilen her iki yumuşak astar maddesi de silikon esaslı olmasına rağmen, Ufi

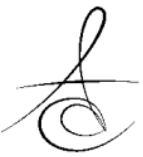


Atatürk Üniv. Diş Hek. Fak. Derg.

] Dent Fac Atatürk Uni

Cilt:25, Sayı:1, Yıl: 2015, Sayfa: 59-65

Gel P tüm protez temizleyicileri ve zaman aralıklarında istatistiksel olarak daha düşük renk değişimi göstermiştir. Elite Soft Relining'in kontrol grubunda da belirgin renk değişimleri tespit edilmiştir. Bu durum, materyallerin kimyasal içeriklerinin farklı olmasından kaynaklanmış olabilir. Ayrıca, hazırlanmaları sırasında oluşan hava kabarcıkları ve materyallerin yüzey pürüzlülükleri de farklı oranlarda renk değişimi oluşmasına neden olmuş olabilir.

$\mathrm{NaOCl}$ biyofilmin kontrolünde kullanılan ve dezenfeksiyonda etkili olan bir ajandır. ${ }^{37}$ Ancak akrilik rezinin rengini beyazlatma olasılığı olduğu rapor edilmiştir. ${ }^{19,38} \mathrm{Bu}$ nedenle hem dezenfeksiyon amaçlı kısa süreli uygulamalarda hem de protez temizleyicisi olarak daha uzun süreli uygulamalarda, NaOCl'nin konsantrasyonu ve uygulama süresi önem taşımaktadır. Protez temizleyicisi olarak günlük kullanımlarda $\% 0.5-\% 1$ konsantrasyondaki $\mathrm{NaOCl} 8$ saat süreyle uygulanmaktadır. ${ }^{38,39} \mathrm{Bu}$ çalışmada da \%0.5 konsantrasyonda $\mathrm{NaOCl}$ nin haftada 3 gün, günde 8 saat kullanımı simüle edilmiştir. Altıncı ayın sonunda Ufi Gel P materyalinde 'fark edilebilir' bir renk değişimine neden olan $\mathrm{NaOCl}$ ile kontrol grubu arasında istatistiksel olarak anlamlı bir farklılık bulunamamıştır. Ancak Elite Soft Relining'in 3 ve 6 ay süreyle $\mathrm{NaOCl}^{\prime}$ ye maruz bırakılması sonucu NBS kriterlerine göre 'çok fazla' renk değişimine neden olmuştur. 'Çok fazla' renk değişimi, materyalin yapısında da önemli bozulmalara işaret ediyor olabilir. Bu nedenle, bu çalışmanın sınırları dahilinde, Elite Soft Relining için NaOCl'nin protez temizleyicisi olarak kullanılmaması önerilebilir.

Alkali peroksitler sodyum perborat veya sodyum karbonat gibi bir efervesan komponente sahiptirler. Efervesan tablet suda çözündüğünde, sodyum bikarbonat ayrışarak alkali peroksit solüsyonu oluşturur. Bu peroksit solüsyonu da oksijen salınımı yaparak debrisleri mekanik yolla uzaklaştırır. ${ }^{40}$ Yüksek peroksit içeriği ve güçlü bir alkali solüsyon içindeki oksijenasyon seviyesinin, protez kaide materyallerine zarar veren bir faktör olduğu belirtilmiştir. ${ }^{4}$ Ancak, bu çalışmada kullanılan alkali peroksit tip protez temizleyicilerinden Corega Tabs ve Fittydent'in neden olduğu renk değişimi her iki yumuşak astar maddesinde de kontrol grubundan anlamlı derecede farklı değildir. Bu çalışmanın bulgularına göre, alkali peroksit tipteki protez temizleyicilerinin yumuşak astar maddelerinde kullanılmasının renk stabilitesi açısından bir sakıncası yoktur.
KURTULMUŞ-YILMAZ, OZAN, RAMOĞLU AKTÖRE, HAMIŞ

Bu çalışmada protez temizleyicilerinin, yumuşak astar maddelerinin sadece renk stabiliteleri üzerine etkisi değerlendirilmiştir. Sonraki çalışmalarda, yumuşak astar maddelerinin sertlik, yüzey pürüzlülüğü, viskoelastisite, akrilik rezine bağlanma direnci gibi başka fiziksel ve mekanik özelliklerin incelenmesi, protez temizleyicilerinin etkisini değerlendirmede daha faydalı olacaktır.

\section{SONUÇ}

Bu çalışmanın sınırları dahilinde, yumuşak astar maddesinin içeriğinin, protez temizleyicilerinin ve uygulama süresinin materyalin renk stabilitesine etkisinin olduğu tespit edilmiştir. Renk stabilitesi, materyalin yıpranması ve zarar görmesi hakkında da klinisyenlere fikir veren bir belirteçtir. Bu nedenle, yumuşak astar maddelerinde protez temizleyicileri nedeniyle oluşan renk farkının materyal seçiminde göz önünde bulundurulması önerilebilir.

\section{KAYNAKLAR}

1. Dootz ER, Koran A, Craig RG. Physical property comparison of 11 soft denture lining materials as a function of accelerated aging. J Prosthet Dent 1993;69:114-9.

2. Wright PS. Characterization of the rupture properties of denture soft lining materials. J Dent Res 1980;59:614-9.

3. Machado AL, Breeding LC, Puckett AD. Effect of microwave disinfection on the hardness and adhesion of two resilient liners. J Prosthet Dent 2005;94:183-9.

4. Nikawa $H$, Iwanaga $H$, Hamada $T$, Yuhta S. Effects of denture cleansers on direct soft denture lining materials. J Prosthet Dent 1994;72:657-62.

5. Aydin AK, Terzioğlu $H$, Akinay AE, Ulubayram $K$, Hasirci N. Bond strength and failure analysis of lining materials to denture resin. Dent Mater 1999;15:211-8.

6. Craig RG, Gibbons P. Properties of resilient denture liners. J Am Dent Assoc 1961;63:382-90.

7. Murata $\mathrm{H}$, Haberham RC, Hamada T, Taguchi N. Setting and stress relaxation behavior of resilient denture liners. J Prosthet Dent 1998;80:714-22. 
8. Garcia RM, Léon BT, Oliveira VB, Del Bel Cury AA. Effect of a denture cleanser on weight, surface roughness, and tensile bond strength of two resilient denture liners. J Prosthet Dent 2003;89:489-94.

9. Garcia LT, Jones JD. Soft liners. Dent Clin North Am 2004;48:709-20.

10. Kawano F, Dootz ER, Koran A 3rd, Craig RG. Sorption and solubility of 12 soft denture liners. J Prosthet Dent 1994;72:393-8.

11. Nikawa H, Yamamoto $T$, Hayashi $S$, Nikawa $Y$, Hamada T. Growth and/or acid production of Candida albicans on soft lining materials in vitro. J Oral Rehabil 1994;21:585-94.

12. Oliveira LV, Mesquita MF, Henriques GE, Consani $\mathrm{RL}$, Fragoso WS. The compatibility of denture cleansers and resilient liners. J Appl Oral Sci 2006;14:286-90.

13. Handa RK, Jagger DC, Vowles RW. Denture cleansers, soft lining materials and water temperature: what is the effect? Prim Dent Care 2008; 15:53-8.

14. Jagger D, Harrison A. Complete Dentures Problem solving. 1st ed. London; British Dental Association:1999. p.17-20.

15. Nikawa $H$, Hamada $T$, Yamamoto $T$, Kumagai $H$. Effects of salivary or serum pellicles on the Candida albicans growth and biofilm formation on soft lining materials in vitro. J Oral Rehabil 1997;24:594-604.

16. Brożek R, Koczorowski R, Rogalewicz R, Voelkel A, Czarnecka $B$, Nicholson JW. Effect of denture cleansers on chemical and mechanical behavior of selected soft lining materials. Dent Mater 2011;27:281-90.

17. Jin C, Nikawa $H$, Makihira S, Hamada T, Furukawa $M$, Murata $H$. Changes in surface roughness and colour stability of soft denture lining materials caused by denture cleansers. J Oral Rehabil 2003;30:125-30.

18. Niarchou A, Ntala P, Pantopoulos A, Polyzois G, Frangou $M$. Effect of immersion cleansing in color stability and hardness of soft denture reliners. J Craniofac Surg 2012;23:426-9.

19. Polyzois GL, Yannikakis SA, Zissis AJ, Demetriou PP. Color changes of denture base materials after disinfection and sterilization immersion. Int J Prosthodont 1997;10:83-9.
20. Ergun G, Nagas IC. Color stability of silicone or acrylic denture liners: an in vitro investigation. Eur J Dent 2007;1:144-51.

21. Anil N, Hekimoglu C, Sahin S. The effect of accelerated aging on color stability of denture liners. J Oral Sci 1998;40:105-8.

22. Mancuso DN, Goiato MC, Zuccolotti BC, Moreno A, dos Santos DM, Pesqueira AA. Effect of thermocycling on hardness, absorption, solubility and colour change of soft liners. Gerodontology 2012;29:e215-9.

23. Kostoulas I, Polyzois G, Mitsoudis A, Kavoura V, Frangou $M$. The effect of accelerated ageing on colour stability of visible light-cured (VLC) chairside denture liners. Gerodontology 2012;29:e239-45.

24. Canay S, Hersek N, Tulunoğlu I, Uzun G. Evaluation of colour and hardness changes of soft lining materials in food colorant solutions. J Oral Rehabil 1999;26:821-9.

25. Saraç D, Saraç YS, Kurt M, Yüzbaşioğlu E. The effectiveness of denture cleansers on soft denture liners colored by food colorant solutions. J Prosthodont 2007;16:185-91.

26. Imirzalioglu $P$, Karacaer $O$, Yilmaz B, Ozmen Msc I. Color stability of denture acrylic resins and a soft lining material against tea, coffee, and nicotine. J Prosthodont 2010;19:118-24.

27. Türker ŞB, Şener ID, Buğurman B, Akkuş E. Silikon bazlı daimi yumuşak astar materyallerinin renk stabilitesinin in vitro olarak değerlendirilmesi. Atatürk Üniv Diş Hek Fak Derg 2008;18:53-9.

28. Polyzois GL, Yannikakis SA, Zissis AJ. Color stability of visible light-cured, hard direct denture reliners: an in vitro investigation. Int J Prosthodont 1999;12:140-6.

29. Hayakawa I, Akiba N, Keh E, Kasuga Y. Physical properties of a new denture lining material containing a fluoroalkyl methacrylate polymer. J Prosthet Dent 2006;96:53-8.

30. Paravina, RD, Powers, JM. Esthetic Color Training in Dentistry. 1st ed. St. Louis; Elsevier Mosby: 2004. p. 24

31. Shotwell JL, Razzoog ME, Koran A. Color stability of long-term soft denture liners. J Prosthet Dent 1992;68:836-8. 
32. Hong G, Murata H, Li Y, Sadamori S, Hamada T. Influence of denture cleansers on the color stability of three types of denture base acrylic resin. J Prosthet Dent 2009;101:205-13.

33. Wagner WC, Kawano F, Dootz ER, Koran A 3rd. Dynamic viscoelastic properties of processed soft denture liners: Part I--Initial properties. J Prosthet Dent 1995;73:471-7

34. Haywood J, Wood DJ, Gilchrist A, Basker RM, Watson $\mathrm{CJ}$. A comparison of three hard chairside denture reline materials. Part II. Changes in colour and hardness following immersion in three commonly used denture cleansers. Eur J Prosthodont Restor Dent 2003;11:165-9.

35. Waters MG, Jagger RG, Polyzois GL. Wettability of silicone rubber maxillofacial prosthetic materials. J Prosthet Dent 1999;81:439-43.

36. Yoeli Z, Miller V, Zeltser C. Consistency and softness of soft liners. J Prosthet Dent 1996;75:412-8.

37. Orsi IA, Junior AG, Villabona CA, Fernandes FH, Ito IY. Evaluation of the efficacy of chemical disinfectants for disinfection of heat-polymerised acrylic resin. Gerodontology 2011;28:253-7.

38. Paranhos Hde F, Davi LR, Peracini A, Soares RB, Lovato $\mathrm{CH}$, Souza RF. Comparison of physical and mechanical properties of microwave-polymerized acrylic resin after disinfection in sodium hypochlorite solutions. Braz Dent J 2009;20:331-5.

39. Davi LR, Peracini A, Ribeiro Nde Q, Soares RB, da Silva $\mathrm{CH}$, Paranhos Hde F, de Souza RF. Effect of the physical properties of acrylic resin of overnight immersion in sodium hypochlorite solution. Gerodontology 2010;27:297-302.

40. Nikawa $H$, Hamada $T$, Yamashiro $H$, Kumagai $H$. A review of in vitro and in vivo methods to evaluate the efficacy of denture cleansers. Int J Prosthodont 1999;12:153-9.

\section{Yazışma Adresi:}

Yrd. Doç. Dr. Sevcan Kurtulmuş-Yılmaz Yakın Doğu Üniversitesi Diş Hekimliği Fakültesi Protetik Diş Tedavisi Anabilim Dalı, Lefkoşa/KKTC Mersin-10 Türkiye Tel: 0392 6802030/2643

e-mail: sevcankurtulmusyilmaz@gmail.com 